\title{
Future drug delivery technologies: benchtop to industry
}

\author{
Md. Jasim Uddin, Irin Sultana, Ayesha Amin Nipa \\ and M. Mohi Uddin Chowdhury \\ Department of Pharmacy, Southern University Bangladesh \\ Dennis Douroumis \\ Faculty of Engineering and Science, University of Greenwich \\ Medway Campus, Chatham Maritime, Kent ME4 4TB, UK.
}

\begin{abstract}
Transmucosal buccal drug delivery system is considered as a future drug delivery technology, always assist to enhance patient compliance mainly for paediatric and geriatric community. The studies aim to develop buccal delivery for delivering a hydrophilic drug, flucloxacillin sodium, across the mucosal route. The buccal films are comprised of a bioadhesive polymer, plasticizer and drug. Optimised films were characterised by measurement of weight, length and width, hardness, thickness, surface $\mathrm{pH}$, moisture content and uptake, swelling study, folding resilience, hydration and entrapment efficiency. Drug release studies were performed for different polymer-plasticizer-drug ratios. Concentration of polymer and plasticizer were influenced on the development, evaluation and release rate of flucloxacillin sodium from the buccal films. In conclusion, these studies reveal that buccal delivery of flucloxacillin sodium can be an alternative route in comparison to conventional route for patient compliance.
\end{abstract}

Keywords Buccal delivery, Solvent casting, Drug release.

Paper type Research paper

\section{Introduction}

Oral drug delivery is the most popular route due its safe and easy administration, but oral route is not always preferable due to the hepatic first pass effect, enzymatic degradation and inactivation at gastric $\mathrm{pH}$. Compared to other mucosal sites (i.e. intestinal, nasal \& rectal); the oral mucosa possesses higher vascularity, less enzyme activity and shows less susceptibility to irritation and damage. The oral mucosa route can be employed for both local and systemic administration of drugs (Boateng, Mani, \& Kianfar, 2013; Boateng \& Okeke, 2014). Previous studies

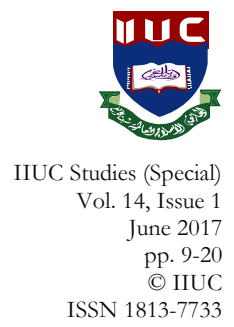




\section{IIUC STUDIES, 14 (Issue 1, Special)}

have also shown that microneedles-mediated transdermal drug delivery are capable of piercing skin in a painless and simple manner making them appropriate for patients who suffer from needlephobia (Nir et al., 2003; Simonsen et al., 1999). As a painless manner, either microneedles mediated transdermal delivery (e.g. anticancer drug) (Uddin et al., 2015) or buccal (e.g. Buprenorphine, Fluticasone Propionate etc.) (Ammar et al., 2016; Bai, Xiang, and Finn, 2016) or even sublingual (e.g. granisetron hydrochloride, apomorphine etc.) (Bilbault et al., 2016; Kalia et al., 2016) delivery has been used successfully in advanced drug delivery technologies.

In order to overcome these disadvantages related to the oral drug delivery and injections, it is necessary to develop a alternative drug delivery system. This research work involves in the physicochemical characterisations of solvent casted buccal films and the release profile of a drug from different amounts of polymer-plasticizer ratios. A model betalactam antibiotic of the penicillin class, flucloxacillin sodium, was chosen as a model drug. The effect of diverse variables (amounts of polymer, plasticizer and drug) and formulation type on drug release characteristics were also investigated. These will facilitate to understand the relationship between drug release characteristics, prepared from mucoadhesive polymer.

\section{Materials and Methods}

\section{Materials}

A model beta-lactam antibiotic of the penicillin class, Flucloxacillin sodium (FluNa)(Molecular Weight: 493.3 Da), was kindly gifted by Albion Laboratories Ltd. (Chittagong, Bangladesh). Polymer X (PolyX) (Molecular Weight 1261.4 Da), Plasticizer Y (PlasY) (Molecular Weight $92.0 \mathrm{Da}$ ), calcium chloride, Potassium chloride, sodium hydroxide and potassium dihydrogen phosphate were purchased from Merck Ltd. (Damstadt, Germany). Nurtient agar media was obtained from HiMedia Laboratories Ltd. (Mumbai, India).

\section{Preparation of blank and drug loaded films}

Polymer and plasticizer were dissolved in distilled water prior adding of drug molecule and casting of the films. PolyX and Plas Y were dissolved slowly into distilled water at room temperature and left for 1 hour in a shaker (Huafeng, China) to achieve complete dissolution and a clear solution. The resulting gel formulations that were left to place for 24 hours to remove all air bubbles that entrapped in the solutions. Clear formulations was poured into the petri dishes $(90 \mathrm{~mm}$ in diameter) and 
dried in an oven (Genlab Limited, Cheshire, UK) at $40^{\circ} \mathrm{C}$ for 24 hrs. The model beta-lactam antibiotic of the penicillin class, FluNa, was used to develop a homogeneous and reproducible drug-loaded buccal film. Drugloaded buccal films were prepared as above with the addition of FluNa to the clear gel solutions before drying in the oven. The composition of blank- and drug-loaded formulations are shown in Table 1.

Table 1. Optimised blank- and drug-loaded buccal films prepared with various amounts of polymers and plasticizer.

\begin{tabular}{llccc}
\hline $\begin{array}{l}\text { Formulation/ } \\
\text { Film Type }\end{array}$ & $\begin{array}{c}\text { Polymer: } \\
\text { Plasticizer }\end{array}$ & $\begin{array}{c}\text { Weight } \\
\text { ratios }\end{array}$ & $\begin{array}{c}\text { Excipient } \\
\text { contents } \\
(\% \mathrm{w} / \mathrm{v})\end{array}$ & $\begin{array}{c}\% \text { FluNa } \\
\text { loading } \\
\text { (w/w) }\end{array}$ \\
\hline F1 (Blank) & PolyX:PlasY & $1: 1$ & $8 \%$ & - \\
F2 (Blank) & PolyX:PlasY & $2: 1$ & $12 \%$ & - \\
F3 (Blank) & PolyX:PlasY & $3: 1$ & $16 \%$ & - \\
F4 (Drug-loaded) & PolyX:PlasY & $1: 1$ & $8 \%$ & 11.1 \\
F5 (Drug-loaded) & PolyX:PlasY & $2: 1$ & $12 \%$ & 7.7 \\
F6 (Drug-loaded) & PolyX:PlasY & $3: 1$ & $16 \%$ & 5.9 \\
F7 (Drug-loaded) & PolyX:PlasY & $1: 1$ & $8 \%$ & 20 \\
F8 (Drug-loaded) & PolyX:PlasY & $2: 1$ & $12 \%$ & 14.3 \\
F9 (Drug-loaded) & PolyX:PlasY & $3: 1$ & $16 \%$ & 11.1 \\
\hline
\end{tabular}

Measurement of weight, length \& width, hardness and thickness

Blank- and drug-loaded buccal films (27 X $15 \mathrm{~mm}$ ) were cut by using customised stainless steel cutter. All blank- and drug-loaded films from each formulation $(n=3)$ were weighed for individual weight individually using digital balanace (Shimadzu Co. Limited, Japan) (Shende et al. 2016). Length \& width (Fig.1) of the optimised films $(n=3)$ were measured using slide calipers (Mitutoyo, Japan). All films ( $n=3$ ) were investigated for hardness using monsanto hardness tester (Sinowon, Guangdong, China). Finally, thickness of the buccal films $(n=3)$ were measured at five different places on the film using manual screw gaudge and calculated for mean \pm standard deviations (SD) (Kumar, Nagabhushanam and Rao, 2013; Yehia, El-Gazayerly and Basalious, 2009).

\section{Folding resilience}

Folding resilience of the films $(n=3)$ were determined manually for the blank- and drug-loaded films. It was calculated approximately by continually folding a small strip of film at the same place till it breaks. The patch folded at the same place without breaking and will propose the value of folding resilience (Boateng, Mani \& Kianfar, 2013; Khana, Agarwal \& Ahuja, 1997). 


\section{IIUC STUDIES, 14 (Issue 1, Special)}

\section{Moisture content}

All buccal films were weighed separately and hold in a desiccator at room temperature for 24 hours, filled with calcium chloride granules. Films were then re-weighed again. The percentage $(\%)$ of moisure content was determined using following method (Madhvi et al., 2013): $\%$ Moisture content $=[$ Initial weight - Final weight $] /$ Final weight $\times 100$.

\section{Moisture uptake}

Individually weighed films were exposed to the saturated solution of potassium chloride ( $84 \%$ relative humidity) after leaving in a desiccators for 24 hours, until a stable weight was attained. The percentage of moisture uptake was calculated using following equation (Madhvi et al., 2013):

$\%$ Moisture uptake $=[$ Final weight - Initial weight $/$ Initial weight $] \times 100$.

\section{Surface pH \& Swelling index (SI)}

The surface $\mathrm{pH}$ of all buccal films $(\mathrm{n}=3)$ were investigated using a digital $\mathrm{pH}$ meter (Hanna Instrument Inc., USA) after an hour on an agar plate $(2 \% \mathrm{w} / \mathrm{v})$ in an incubator maintained at $37 \pm 0.2^{\circ} \mathrm{C}$. Swelling index (SI) was also measured using the same parameters. Swelling index was calculated using following formula (Nair et al., 2013; Perioli et al., 2004; Wu, Chen and Jin, 2016):

$\mathrm{SI}=[\mathrm{Ws}-\mathrm{Wd}] / \mathrm{Wd} \times 100$; where $\mathrm{Wd}=$ Dry weight of buccal film .Ws $=$ Weight of film after swelling.

\section{Percent elongation}

The percent elongation of the buccal films were calculated using the following formula (Madhvi et al., 2013):

Percent Elongation = Lx100/Lo; Where, L= Increase in length of buccal film, Lo=Initial length of buccal film.

\section{Hydration and entrapment efficiency}

All the films (F4 to F9) ( $\mathrm{n}=3$ ) were dissolved in $50 \mathrm{ml}$ of phosphate buffer $\mathrm{pH} 6.5$ with a rotation of 50 at $37^{\circ} \mathrm{C}$ until entire dissolution of the films.

The buffer solution was prepared by $\mathrm{KH}_{2} \mathrm{PO}_{4}$ and $\mathrm{NaOH}(0.1 \mathrm{M})$ to get a $\mathrm{pH}$ of 6.5 simulating salivary conditions. The entrapment efficiencies of the films were calculated using following formula (Boateng, Mani and Kianfar, 2013; Shende et al., 2016; Okeke and Boateng, 2016):

$\%$ Drug entrapment efficiency $=$ [Initial weight-Final weight/Initial weight] $\times 100$. 


\section{In vitro release studies of drug-Loaded oral films}

In vitro release studies of FluNa-loaded buccal films were investigated using $50 \mathrm{ml}$ of phosphate buffer of $\mathrm{pH} 6.5$ at $37^{\circ} \mathrm{C}$ at 50 r.p.m for an hour. At planned intervals (0-60 minutes), $10 \mathrm{ml}$ of aliquots were taken out from the media and anlalysed at $219 \mathrm{~nm}$ using $U V$-spectrophotometer (Boekel \& Co., Hamburg, Germany) for the quantification of FluNa. Aliquots were replaced with fresh buffer medium at the different intervals to uphold sink condition (Boateng, Mani \& Kianfar, 2013).

\section{Results and Discussion}

For the rationale of the research, FluNa-loaded mucoadesive buccal films were manufactured with PolyX and PlasY system using a solvent casting method. Un-plasticized blank film with PolyX was brittle in nature and firm to remove from the petri dishes. PlasY was dissolved to the formulations, to make the buccal films more elastic and for the removal of its brittleness. The optimal amount of PlasY was $1 \%(\mathrm{w} / \mathrm{w})$ in both the blank and drug-loaded films. Drug-loaded films were easier to remove from the petri dishes than the blank films.
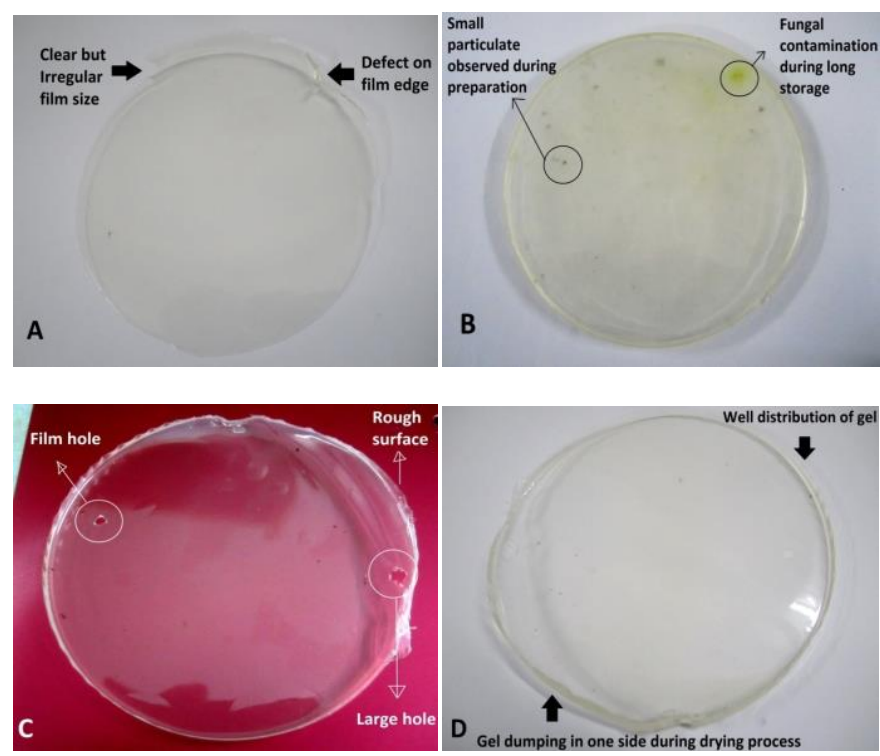

Fig.1. Digital photographs of manufacturing defects during the optimisation process of the blank buccal films. 


\section{IIUC STUDIES, 14 (Issue 1, Special)}
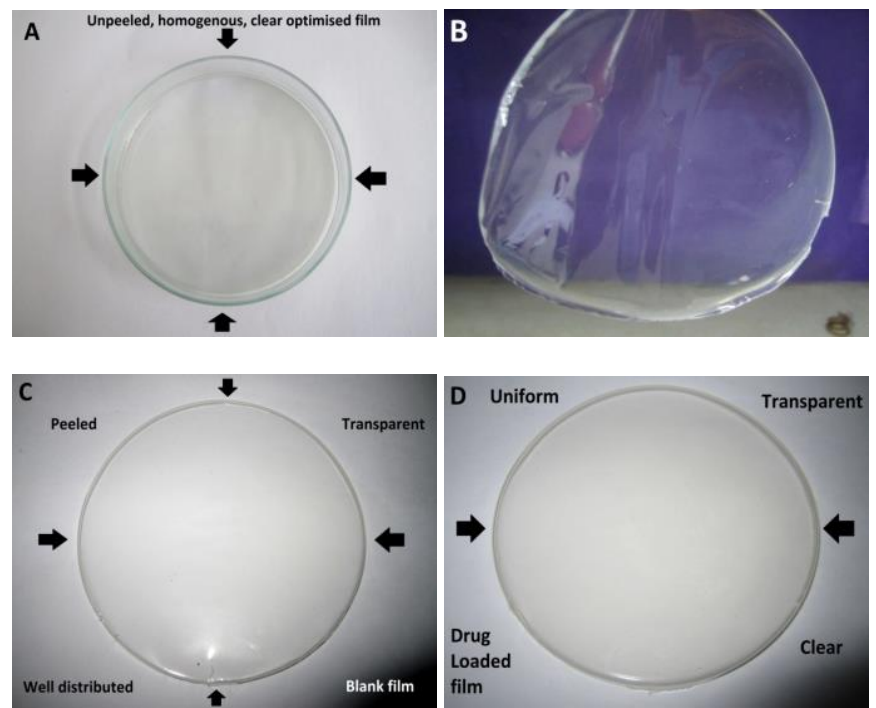

Fig.2. Digital images of solvent casted optimised blank- and drug-loaded films for the delivery of FluNa.
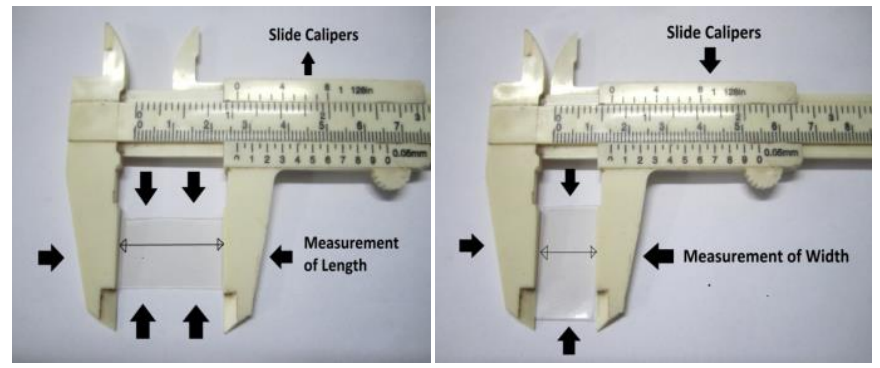

Fig. 3. Measurement of length and width of transmucosal buccal film using slide calipers.

Table.2a. Physicochemical characterisation of mucoadhesive buccal film (Visual appearance,Weight, Length \& Width) (Mean \pm SD).

\begin{tabular}{ccccc}
\hline Formulation & Visual appearance & Weight $(\mathrm{mg})$ & Length $(\mathrm{mm})$ & Width $(\mathrm{mm})$ \\
\hline F1 & Transparent & $154.0 \pm 3.2$ & $27.2 \pm 0.3$ & $15.0 \pm 0.5$ \\
F2 & Transparent & $242.1 \pm 3.1$ & $26.8 \pm 0.6$ & $15.2 \pm 0.3$ \\
F3 & Transparent & $332.0 \pm 0.6$ & $27.0 \pm 0.5$ & $15.2 \pm 0.3$ \\
F4 & Transparent & $165.3 \pm 2.5$ & $27.5 \pm 0.3$ & $15.2 \pm 0.2$ \\
F5 & Transparent & $257.1 \pm 2.1$ & $27.5 \pm 0.2$ & $15.5 \pm 0.1$ \\
F6 & Opaque & $338.0 \pm 2.9$ & $27.5 \pm 0.1$ & $15.5 \pm 0.2$ \\
F7 & Transparent & $185.4 \pm 3.8$ & $27.5 \pm 0.3$ & $15.5 \pm 0.1$ \\
F8 & Transparent & $272.3 \pm 4.0$ & $27.5 \pm 0.3$ & $15.2 \pm 0.2$ \\
F9 & Opaque & $365.1 \pm 7.0$ & $27.5 \pm 0.1$ & $15.0 \pm 0.0$ \\
\hline
\end{tabular}


Future drug delivery 15

Table.2b. Physicochemical characterisation of mucoadhesive buccal film (Thickness at the five places) (Mean \pm SD).

\begin{tabular}{cccccc}
\hline Formulation & Upper left & Below left & $\begin{array}{c}\text { Middle } \\
\text { centre }\end{array}$ & Upper right & Below right \\
\hline F1 & $0.11 \pm 0.02$ & $0.13 \pm 0.01$ & $0.12 \pm 0.01$ & $0.11 \pm 0.01$ & $0.10 \pm 0.01$ \\
F2 & $0.11 \pm 0.01$ & $0.11 \pm 0.02$ & $0.11 \pm 0.01$ & $0.10 \pm 0.02$ & $0.12 \pm 0.01$ \\
F3 & $0.11 \pm 0.01$ & $0.11 \pm 0.01$ & $0.11 \pm 0.01$ & $0.10 \pm 0.01$ & $0.12 \pm 0.01$ \\
F4 & $0.11 \pm 0.02$ & $0.11 \pm 0.01$ & $0.12 \pm 0.02$ & $0.10 \pm 0.02$ & $0.11 \pm 0.02$ \\
F5 & $0.11 \pm 0.01$ & $0.10 \pm 0.01$ & $0.11 \pm 0.01$ & $0.10 \pm 0.01$ & $0.11 \pm 0.01$ \\
F6 & $0.10 \pm 0.01$ & $0.11 \pm 0.01$ & $0.11 \pm 0.01$ & $0.11 \pm 0.02$ & $0.11 \pm 0.01$ \\
F7 & $0.12 \pm 0.01$ & $0.12 \pm 0.02$ & $0.12 \pm 0.02$ & $0.10 \pm 0.01$ & $0.11 \pm 0.02$ \\
F8 & $0.12 \pm 0.01$ & $0.11 \pm 0.01$ & $0.14 \pm 0.04$ & $0.11 \pm 0.02$ & $0.12 \pm 0.01$ \\
F9 & $0.11 \pm 0.01$ & $0.12 \pm 0.01$ & $0.12 \pm 0.02$ & $0.11 \pm 0.02$ & $0.11 \pm 0.01$ \\
\hline
\end{tabular}

Table.2c. Physicochemical characterisation of mucoadhesive buccal film (Folding resilience, percent moisture content, percent moisture uptake \& surface $\mathrm{pH})(\mathrm{Mean} \pm \mathrm{SD})$.

\begin{tabular}{ccccc}
\hline Formulation & $\begin{array}{c}\text { Folding } \\
\text { resilience }\end{array}$ & $\begin{array}{c}\% \text { Moisture } \\
\text { content }\end{array}$ & $\begin{array}{c}\% \text { Moisture } \\
\text { uptake }\end{array}$ & $\begin{array}{c}\text { Surface } \\
\mathrm{pH}\end{array}$ \\
\hline F1 & $125.0 \pm 1.0$ & $13.3 \pm 1.5$ & $25.0 \pm 3.0$ & $6.6 \pm 0.1$ \\
F2 & $120.0 \pm 1.0$ & $25.3 \pm 1.5$ & $53.0 \pm 1.3$ & $6.6 \pm 0.1$ \\
F3 & $114.7 \pm 0.6$ & $59.0 \pm 1.0$ & $65.6 \pm 3.1$ & $6.7 \pm 0.2$ \\
F4 & $116.3 \pm 0.6$ & $18.2 \pm 1.8$ & $22.1 \pm 2.8$ & $6.5 \pm 0.0$ \\
F5 & $110.7 \pm 3.1$ & $27.2 \pm 0.8$ & $35.2 \pm 3.5$ & $6.5 \pm 0.0$ \\
F6 & $101.3 \pm 2.5$ & $52.8 \pm 1.7$ & $50.6 \pm 5.9$ & $6.6 \pm 0.1$ \\
F7 & $117.3 \pm 1.5$ & $17.7 \pm 0.4$ & $27.1 \pm 3.5$ & $6.6 \pm 0.1$ \\
F8 & $105.3 \pm 1.0$ & $18.8 \pm 1.6$ & $48.5 \pm 8.7$ & $6.5 \pm 0.1$ \\
F9 & $80.2 \pm 2.5$ & $56.7 \pm 2.2$ & $65.2 \pm 7.4$ & $6.6 \pm 0.1$ \\
\hline
\end{tabular}

Table.2d. Physicochemical characterisation of mucoadhesive buccal film (Swelling index, Percent elongation, Hydration \& Entrapment efficiency) (Mean \pm SD).

\begin{tabular}{ccccc}
\hline Formulation & $\begin{array}{c}\text { \% Swelling } \\
\text { index }\end{array}$ & \% Elongation & $\begin{array}{c}\text { Hydration } \\
\text { Time (min) }\end{array}$ & $\begin{array}{c}\% \text { Entrapment } \\
\text { efficiency }\end{array}$ \\
\hline F1 & $100 \pm 0.0$ & $105.2 \pm 3.0$ & $5-10$ & - \\
F2 & $100 \pm 0.0$ & $118.0 \pm 3.2$ & $7-15$ & - \\
F3 & $100 \pm 0.0$ & $101.6 \pm 2.0$ & $15-20$ & - \\
F4 & $100 \pm 0.0$ & $104.6 \pm 0.9$ & $5-10$ & $93.3 \pm 2.8$ \\
F5 & $100 \pm 0.0$ & $105.9 \pm 1.2$ & $7-15$ & $94.6 \pm 3.7$ \\
F6 & $100 \pm 0.0$ & $108.6 \pm 1.1$ & $15-20$ & $96.7 \pm 2.3$ \\
F7 & $100 \pm 0.0$ & $104.5 \pm 0.9$ & $5-10$ & $95.0 \pm 3.3$ \\
F8 & $100 \pm 0.0$ & $104.1 \pm 0.7$ & $7-15$ & $96.2 \pm 2.5$ \\
F9 & $100 \pm 0.0$ & $112.2 \pm 1.5$ & $15-20$ & $97.0 \pm 1.2$ \\
\hline
\end{tabular}

All films were transparent, except F6 and F9 (drug-loaded), the concentration of PolyX and FluNa was higher than other formulations (Table.2a). Initially, blank films were optimised for physicochemical characterisations. Film defects, such as irregular film size, defects on the edge, observation of small particulate, fungal contamination, film hole, 


\section{IIUC STUDIES, 14 (Issue 1, Special)}

rough surface and gel dumping in one side (Fig.1), were investigate during this research. However, uniform, transparent, clear and well distributed films were developed using appropriate amount of polymer and plasticizer (Fig.2). Physicochemical characterisation was performed to study the properties of each buccal film. Increasing the amount of PolyX, PlasY and FluNa, weight of the film increased rapidly (Table.2a). Length and width of the films showed almost a constant size and shape after cut in specific size and shape (Table.2a). Thickness of the films was in the range between 0.10 to $0.14 \mathrm{~mm}$ which indicate the formation of thin buccal films (Table.2b). Folding resilience of the films were F1 $>$ F2 $>$ F3 (blank), $\mathrm{F} 4>\mathrm{F} 5>\mathrm{F} 6$ and F7>F8 $>$ F9 (drug loaded). PolyX and PlasY influenced on the folding resilience of each film, high the ratios of plasticizer exhibit upper folding resilience (Table.2c). This trends is also same for percent moisture content and uptake as well. Hydrophilic drug and polymer has a great ability to contain and uptake moisture from the environment. Surface $\mathrm{pH}$ was in the range between 6.5-6.8 for all formulations (Table.2c). An acidic or alkaline $\mathrm{pH}$ may irritate the buccal mucosa and affect the degree of polymer hydration. Therefore, the surface $\mathrm{pH}$ of the buccal films were selected to optimise both the mucoadhesion and drug release (Wu, Chen, Jin, 2016). All formulations were dissolved after completely an hour for hydrophilic drug and polymer, ability to swell rapidly (Table.2d). Plasticizer has direct influence on the plastic properties or elongation properties (Table.2d). Hence, the entrapment efficiencies of the drugs were $93 \%-98 \%$ for all formulations.

To study the release profile of $\mathrm{FluNa}$ at different polymer concentrations, FluNa-loaded transmucosal buccal films were tested into phosphate buffer at $\mathrm{pH} 6.5$ and the release profile for each formulations was examined for an hour. FluNa was chosen in order to investigate the effect of drug hydrophilicity, entrapment efficiencies and formulation. Fig.5a shows the release of the FluNa where the increase of PolyX ratio, resulted in slower release rates for 1:1 and 2:1 PolyX/PlasY ratios. The release rates were $71 \%$ and $45 \%$ after 30 mins whereas for 3:1 ratio, controlled release was observed. After 60 minutes all formulations (F4-F6) showed complete release of FluNa. Similar results were observed for FluNa-loaded formulation (F7-F9) and the dissolution of PolyX was the rate-limiting factor for the drug release (Fig.5b). The FluNa release patterns are related to those of F4-F6 but with slightly quicker rate which may occur due to higher water solubility of both FluNa and PolyX.

However, FluNa release rates were significantly lower at the beginning, until the full hydration of film into the buffer medium. The empty amount is therefore expected to be full by the external liquid 
diffusing into the buccal film and thereby increasing the dissolution of the film. In addition, the thick film surface produced on the swollen film surface is competent of avoiding disintegration and controlling additional water diffusion (Yehia, El-Gazayerly and Basalious, 2009).

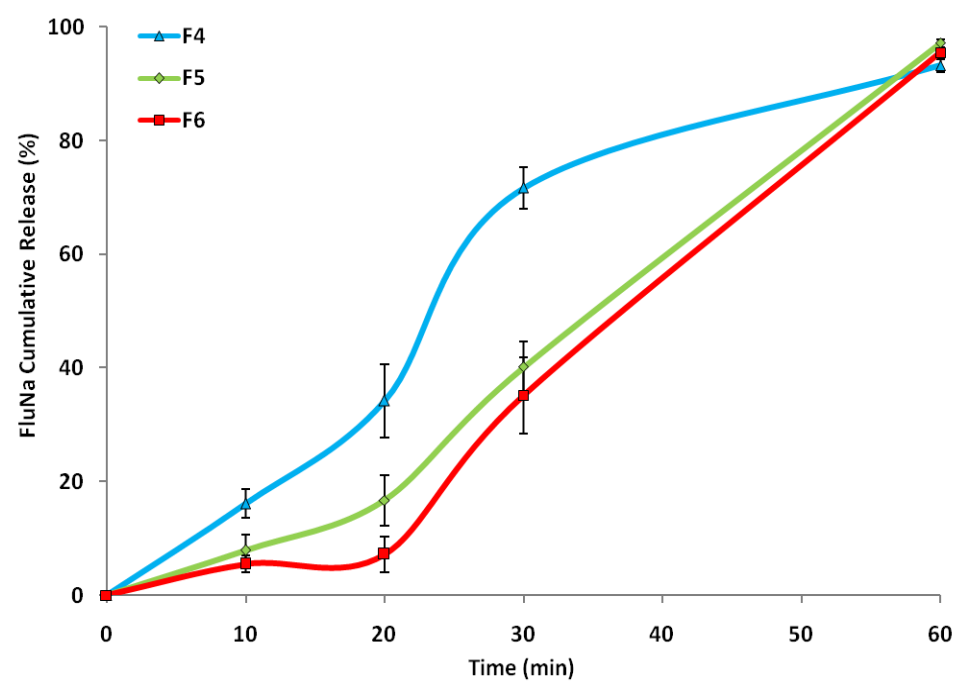

(a)

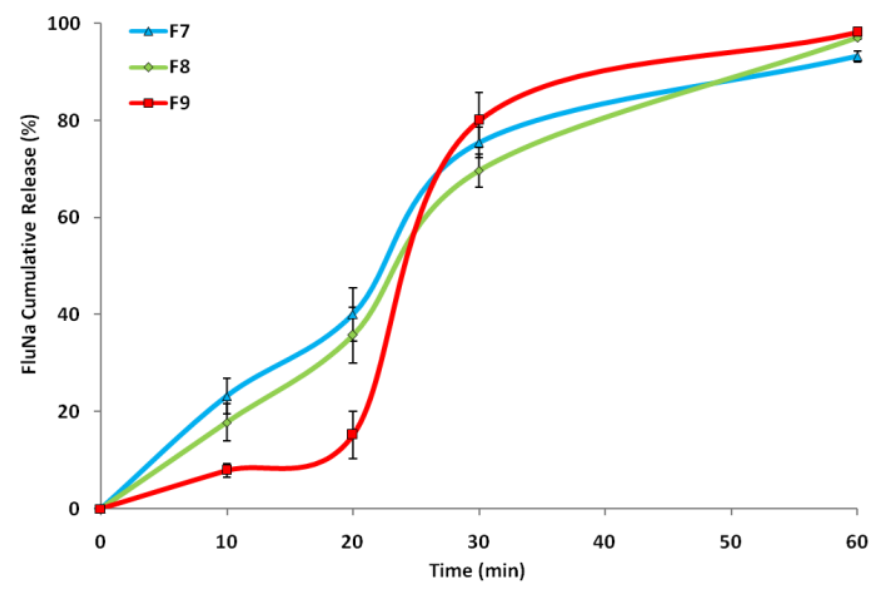

(b)

Fig.5. In vitro release profile of FluNa loaded different (a) formulations (F4-F6), (b) formulations (F7-F9). 


\section{IIUC STUDIES, 14 (Issue 1, Special)}

\section{Conclusions}

In conclusion, buccal films were loaded with various amounts of FluNa and successfully released from the films. The optimisation of blank buccal films were uniform, reproducible and accurate in terms of drug loading and drug release profile. The hydrophilic drug, FluNa, showed fast release profiles with most of the substances released within an hour. This release phenomenon was achieved using PolyX, a polymer with high solubilising capacity, which increased the drug release rates. Transmusocal buccal film is a new technology for delivering a wide range of active pharmaceutical substances compared to conventional approaches and can be further used for protein and peptide delivery.

\section{Acknowledgment}

This research work was funded and organised by Southern University Bangladesh, Chittagong.

\section{References}

Ammar, H. O., Ghorab, M. M., Mahmoud, A. A., \& Shahin, H. I. (2016). Design and In vitro/In vivo evaluation of ultra-thin mucoadhesive buccal film containing fluticasone propionate. AAPS PharmSciTech, 1-11.

Bai, S. A., Xiang, Q., \& Finn, A. (2016). Evaluation of the pharmacokinetics of single-and multiple-dose buprenorphine buccal film in healthy volunteers. Clinical Therapentics, 3, 358-369.

Bilbault, T., Taylor, S., Walker, R., Grundy, S. L., Pappert, E. J., \& Agro, A. (2016). Buccal mucosal irritation studies of sublingual apomorphine film (APL-130277) in Syrian golden hamsters. Therapentic Delivery, 7, 611-618.

Boateng, J. S., \& Okeke, O. (2014). Chitosan-based films for the sustained release of peptides: A new era in buccal delivery? Therapentic Delivery, 5, 497-500.

Boateng, J., Mani, J., \& Kianfar, F. (2013). Improving drug loading of mucosal solvent cast films using a combination of hydrophilic polymers with amoxicillin and paracetamol as model drugs. BioMed Research International, 2013.

Kalia, V., Garg, T., Rath, G., \& Goyal, A. K. (2016). Development and evaluation of a sublingual film of the antiemetic granisetron hydrochloride, artificial cells. Nanomedicine, and Biotechnology, 44, 842-846.

Khana, R., Agarwal, S. P., \& Ahuja, A. (1997). Preparation and evaluation of muco-adhesive buccal films of clotrimazole for oral Candida infections. Indian Journal of Pharmaceutical Sciences, 59, 299-305. 
Kumar, S. K., Nagabhushanam, M. V., \& Rao, K. S. (2013). Formulation development and in vivo evaluation of zolmitriptan oral dissolving films. International Journal of Pharma and Bio Sciences, 4, 638-654.

Madhavi, B. R., Murthy, V. S., Rani, A. P., \& Kumar, G. D. (2013). Buccal film drug delivery system-an innovative and emerging technology. Journal of Molcular Pharmceutics and Organic Process Research, 1, 1-6.

Nair, A. B., Kumria, R., Harsha, S., Attimarad, M., Al-Dhubiab, B. E., \& Alhaider, I. A. (2013). In vitro techniques to evaluate buccal films. Journal of Controlled Release, 166, 10-21.

Nir, Y., Paz, A., Sabo, E., \& Potasman, I. (2003). Fear of injections in young adults: Prevalence and associations. American Journal of Tropcal Medicine and Hygiene, 68, 341-344.

Okeke, O. C., \& Boateng, J. S. (2016). Composite HPMC and sodium alginate based buccal formulations for nicotine replacement therapy. International Journal of Biological Macromolecules, 91, 31-44.

Perioli, L., Ambrogi, V., Angelici, F., Ricci, M., Giovagnoli, S., Capuccella, M., \& Rossi, C. (2004). Development of mucoadhesive patches for buccal administration of ibuprofen. Journal of Controlled Release, 99, 73-82.

Shende, P. K., Gaud, R. S., Bakal, R., \& Yeole, Y. (2016). Clove oil emulsified buccal patch of serratiopeptidase for controlled release in toothache. Journal of Bioequivalence \& Bioavailability, 8, 134-139.

Simonsen, L., Kane, A., Lloyd, J., Zaffran, M., \& Kane, M. (1999). Unsafe injections in the developing world and transmission of bloodborne pathogens: A review. Bull. World Health Organ, 77, 789-800.

Uddin, M. J., Scoutaris, N., Klepetsanis, P., Chowdhry, B., Prausnitz, M. R., \& Douroumis, D. (2015). Inkjet printing of transdermal microneedles for the delivery of anticancer agents. International Journal of Pharmaceutics, 494, 593-602.

Wu, W., Chen, W., \& Jin, Q. (2016). Oral mucoadhesive buccal film of ciprofloxacin for periodontitis: Preparation and characterization. Tropical Journal of Pharmaceutical Research, 15, 447-451.

Yehia, S. A., El-Gazayerly, O. N., \& Basalious, E. B. (2009). Fluconazole mucoadhesive buccal films: In vitro/in vivo performance. Current Drug Delivery, 6, 17-27.

\section{Corresponding author}

Md. Jasim Uddin can be contacted at: pharmacistjasim@gmail.com 
20 IIUC STUDIES, 14 (Issue 1, Special) 